\title{
AISLAMIENTO, SELECCIÓN Y CARACTERIZACIÓN DE CEPAS DEL GÉNERO LACTOBACILLUS AISLADAS DE LÍQUIDO RUMINAL VACUNO EN LA ZONA SUR DEL LAGO, VENEZUELA
}

\section{ISOLATION, SELECTION AND CHARACTERIZATION OF LACTOBACILLUS GENUS STRAINS FROM CATTLE RUMEN FLUID IN SOUTH LAKE AREA, VENEZUELA}

\author{
JAMINTO PÉREZ, ${ }^{1}$ Ing, ELIZABETH ROCHA, ${ }^{1}$ Ing, DAVID UZCATEGUI, ${ }^{1}$ M.Sc, \\ YANI ARANGUREN,${ }^{2}$ M.Sc, ELWI MACHADO, ${ }^{2}$ M.Sc.
}

${ }^{1}$ Universidad Nacional Experimental Sur del Lago, Programa de Ingeniería en producción agropecuaria, Zulia - Venezuela. ${ }^{2}$ Universidad Nacional Experimental Sur del Lago, Laboratorio de Microbiología de alimentos, Zulia - Venezuela

\section{Key words:}

Probiotic,

Pathogenic bacteria, Animal feed.

\section{Abstract}

Lactic acid bacteria of Lactobacillus genus were isolated from cattle rumen fluid in the Colon, was carried out by sampling animals post-mortem at the at slaughter and distribution service meat "FIBASA". These samples were diluted to different concentrations ranging from $10^{-1}-10^{-7}$ and plated on, thereby obtaining bacterial colonies, which were evaluated in vitro with growth tests, shape, color, size, mobility, presence of spores, lactic acid production, fermentation of carbohydrates, acid resistance (2.5 to 6.5$)$ and temperature profiles from $\left(4{ }^{\circ} \mathrm{C}-50{ }^{\circ} \mathrm{C}\right)$. This was achieved characterize two strains (L1 and L2), whose biochemical and morphological analysis places them within the genus Lactobacillus, These strains have high antagonistic activity against pathogenic bacteria which makes them a probiotic potential, for animal feed.

\section{Palabras Clave:}

Probiótico,

Bacterias patógenas, Alimentación animal.
INFORMACIÓN Recibido: $14-10-2015$; Aceptado: 25-11-2015. Correspondencia autor: Perez.a.jaminto@gmail.com elwimachado@gmail.com

\section{Resumen}

La caracterización de bacterias ácido lácticas del género Lactobacillus aisladas y seleccionadas de líquido ruminal vacuno en el Municipio Colon del estado Zulia, se llevó a cabo mediante el muestreo de animales post-morten en el centro de matanza y servicio de distribución de carnes "FIBASA". Dichas muestras fueron diluidas a diferentes concentraciones desde $10^{-1}-10^{-7}$ y sembradas en placas, obteniendo con ello colonias bacterianas, las cuales fueron evaluadas in-vitro con pruebas de crecimiento, forma, color, tamaño, movilidad, presencia de esporas, producción de ácido láctico, fermentación de carbohidratos, resistencia a ácidos $(2,5-6,5)$ y perfiles térmicos desde $\left(4^{\circ} \mathrm{C}-50^{\circ} \mathrm{C}\right)$. Con ello se logró caracterizar dos cepas $\left(L_{1}\right.$ y $L_{2}$, cuyo análisis bioquímico y morfológico las ubica dentro del género Lactobacillus, estas cepas presentaron una alta actividad antagónica contra bacterias patógenas, los que las convierte en un potencial probiótico para la alimentación animal. 


\section{Introducción}

Ciertos antibióticos se han utilizado en la alimentación animal para estimular el crecimiento durante más de cinco décadas. Con el aumento de la resistencia a los antibióticos en los microorganismos patógenos, existe una creciente presión para reducir el uso de antibióticos promotores del crecimiento de los animales (HSUEH et al., 2014). Una de las posibles alternativas a los antibióticos son los probióticos, que son suplementos microbianos vivos que confieren un efecto beneficioso en el huésped cuando se administran en cantidades adecuadas (GUARNER y SCHAAFSMA, 1998). Bacterias del genero Lactobacillus son uno de los tipos de probiótico más comunes utilizados actualmente en aditivos para piensos (ANADÓN et al., 2006), mejorando efectivamente la tasa de crecimiento, la eficiencia y la resistencia a las enfermedades de los animales de granja (PATTERSON y BURKHOLDER, 2003).

Los lactobacilos comprenden un grupo de bacterias no esporulantes, catalasa negativos y Gram-positivas en forma de bastón. Generalmente habitan el tractos gastrointestinales de mamíferos y aves, productos lácteos y plantas en descomposición (CHENG et al., 2014). Muchas cepas del genero Lactobacillus, son considerados seguros (GRAS), con múltiples efectos beneficiosos sobre la salud animal y humana. Atribuido principalmente a su capacidad para unirse a la pared intestinal y competir con patógenos intestinales, a la producción de bacteriocinas como como peróxido de hidrógeno y reuterina y/o sustancia antimicrobiana que tienen efectos inhibidores sobre la metanogénesis en rumiantes (SORIANO et al., 2014).

\section{Materiales y métodos}

Extracción y Obtención de Líquido Ruminal (L.R): Para ello se tomaron muestras de líquido ruminal de tres vacunos (machos de edad adultas), de etapa postmorten en el centro de matanza y servicio de distribución de carnes "FIBASA" (Frigorífico Industrial Santa Bárbara S.A). La extracción se hizo mediante una incisión en el rumen colectando tres muestras de $15 \mathrm{ml}$ por animal en tubos Falcon $®$ de $15 \mathrm{ml}$ estériles.

Siembra, Aislamiento y Selección de los Aislados: Se realizaron diluciones seriadas con solución salina fisiológica $(0,9 \% \mathrm{NaCl})$ hasta la dilución $10^{-7}$. Las diluciones $10^{-5}, 10^{-6}$ y $10^{-7}$ fueron sembradas en superficie en agar Man, Rogosa y Sharpe (MRS) e incubadas en condiciones de microaerofília, por 48 horas a $35^{\circ} \mathrm{C}$, con observación por cada 12 horas. Trascurridas 48 horas de incubación, se seleccionaron colonias con características propias del genero Lactobacillus (colonias pequeñas de 2 - 3,5 mm, márgenes enteros, color blanco o crema). Y se repicaron en siembra por agotamiento en agar MRS (RONDÓN et al., 2008; VALLEJO et al., 2008).

Tinción Gram, Movilidad y Producción de Esporas: A las colonias aisladas se le realizó una coloración de Gram para determinar la composición de la pared bacteriana, forma, disposición y presencia o ausencia de esporas. La movilidad se evaluó mediante una muestra en fresco.

Oxidasa y Catalasa: La prueba de oxidasa se aplicó para evidenciar el sistema citocromo oxidasa el cual reacciona con el reactivo de Kovac. La prueba de catalasa se realizó usando como substrato peróxido de hidrogeno.

Producción de Ácido Láctico: Los aislados se sembraron en placas con agar MRS usando como indicador de $\mathrm{pH}$ Verde de Bromocresol al 1\%, Este último se prepara al $50 \%$ y es esterilizado por separado y agregado al medio inmediatamente antes de verter en las placas. Una vez inoculadas las placas, fueron incubadas bajo las condiciones antes descritas (RONDÓN et al., 2008; VALLEJO et al., 2008).

Fermentación de carbohidratos: Las cepas estudiadas se cultivaron en caldo a base de peptona (7gr/L), y un carbohidrato fermentable (5gr/L) (Lactosa, Arabinosa, Manosa, Xilosa, Manitol, Celobiosa, Inositol, D- Sorbitol, Galactosa, Glucosa, Fructosa, Maltosa o Sacarosa), la producción de ácido se evidencio con rojo de metilo al $1 \%$ después de 48 horas de incubación y el $\mathrm{CO}_{2}$ producto de la fermentación se midió con campanas de Durham. Los caldos fueron inoculados con una suspensión bacteriana de 0,5 D.O. Según la escala Mac Farland (GUSILS et al., 2001).

Resistencia a ácidos: Se realizó una escala de $\mathrm{pH}$ con una solución amortiguadora de 0,1 M Tris-ácido acético para $\mathrm{pH} 2,5 ; 3 ; 3,5 ; 4 ; 4,5$ y 5,0 y Tris- $\mathrm{NaOH}$ para $\mathrm{pH} 5,5 ; 6$ y 6,5 . Las soluciones amortiguadoras se incubaron con una suspensión bacteriana $(0,5 \mathrm{DO}$ en la escala Mc Farland) 1:1 por 4 horas en microaerofília con subsiguientes siembras en superficie de agar MRS (GUTIÉRREZ RAMÍREZ et al., 2007)

Determinación de la Temperatura Óptima de Crecimiento: Las colonias aisladas se cultivaron en placas con Agar MRS a través de siembras en superficie incubándose en microaerofília por 48 horas a diferentes temperaturas $\left(4^{\circ} \mathrm{C} ; 18^{\circ} \mathrm{C} ; 20^{\circ} \mathrm{C} ; 25^{\circ} \mathrm{C} ; 30^{\circ} \mathrm{C} ; 35^{\circ} \mathrm{C}\right.$; $38^{\circ} \mathrm{C} ; 40^{\circ} \mathrm{C} ; 45^{\circ} \mathrm{C}$ y $50^{\circ} \mathrm{C}$ ) (GUTIÉRREZ RAMÍREZ et al., 2007).

Identificación Molecular: La identificación molecular fue aplicada solo a uno de los aislados $\left(L_{2}\right)$. Esta se llevó a cabo, a través de un análisis comparativo de 
secuencias nucleotídicas del gen que codifica para ADN Ribosomal 16S, empleando para ello la técnica de PCR colonia (LANE et al., 1985).

Inhibición de bacterias patógenas: Las cepas denominadas L1, L2 y Lactobacillus brevis (control) se cultivaron en MRS semisólido e incubadas a $35^{\circ} \mathrm{C}$ durante $16 \mathrm{~h}$ en microaerofilia, luego se mezclaron 20 $\mu \mathrm{L}$ del cultivo overnight en $500 \mathrm{~mL}$ de agar MRS y se sembraron $30 \mu \mathrm{L}$ de la mezcla en pocillos practicados en placas con agar MRS. Se incubó durante 12-14 h a $35^{\circ} \mathrm{C}$ y posteriormente se adicionó otra capa de $10 \mathrm{~mL}$ de agar cerebro-corazón $(0,8 \%$ agar) conteniendo 50 $\mathrm{mL}$ de la cepa indicadora $\left(10^{6}-10^{7} \mathrm{UFC} / \mathrm{mL}\right)$ y se dejó incubar durante $24 \mathrm{~h}$. La actividad antagónica se detectó por la presencia de halos de inhibición alrededor de los pocillos (VALLEJO et al., 2008). Las cepas indicadoras empleadas para dicha prueba fueron: Salmonella sp, Pseudomona aeruginosa, Pseudomona putida, Staphilococcus sp, Staphilococcus aureus, Echerichea coli, Echerichea coli enteromasiva, Bacillus spp, Bacillus aminoliquefacium, Bacillus subtilis, Enterococcus sp., Enterococcus fecali, Moraxela catarralis y Enterobacteria. Dichas cepas fueron obtenidas del Laboratorio de Biotecnología de microorganismos de la Universidad de los Andes, siendo reactivados en agar $\mathrm{BHI}$, caldos Nutritivos y sembradas en Agar Nutritivo.

\section{Resultados y discusión}

Siembra, Aislamiento y Selección de los Aislados: Mediante el aislamiento se observó la presencia de diversos tipos de microorganismos, con características similares a hongos filamentosos, levaduras y bacterias. Ello permitió la selección de dos colonias identificadas como $L_{1} y L_{2}$, cuyas características macromorfológicas eran semejantes a las descritas para el género Lactobacillus: pequeñas 2 - 3,5 mm aproximadamente, convexas, con márgenes enteros, opacas y sin pigmentos, características propias de la especie (BOONE et al., 2001). El aislamiento de estas colonias propias del genero Lactobacillus no es de extrañar, dado que el rumen de los vacunos esta colonizado por cepas del género (ÁVILA et al., 2010a; ÁVILA et al., 2010b)

Tinción de Gram, Movilidad y Presencia de Esporas: Las bacterias se presentaron como bacilos Gram-positivos, de borde redondeado, con una disposición en cadena o individuales (Tabla 1). Las características morfológicas evidenciadas en microscopio, fueron reportadas como propias del grupo de BAL específicamente las del género Lactobacillus ( BOONE et al., 2001; ÁVILA et al., 2010b). La ausencia de movilidad y de espora en las cepas de $L_{1}$ y $L_{2}$ son características propias del genero Lactobacillus.
Tabla 1. Características microscópicas y bioquimicas de Los aislados $L_{1}, L_{2}$ y $L$. brevis.

\begin{tabular}{|c|c|c|c|c|c|c|c|}
\hline Colonias & T.G & Forma & Disposición & Espora & Catalasa & Oxidasa & P. A.L \\
\hline L1 & + & Bacilo & $\begin{array}{l}\text { Cadenas e } \\
\text { Individual }\end{array}$ & - & - & - & + \\
\hline L2 & + & Bacilo & $\begin{array}{l}\text { Cadenas e } \\
\text { Individual }\end{array}$ & - & - & - & + \\
\hline L. brevis & + & Bacilo & Cadenas & - & - & - & + \\
\hline
\end{tabular}

T.G: tinción de gram; P.A.L: producción de ácido láctico; (+): positivo(a); (-) negativo(a)

Producción de ácido láctico: Las cepas $\mathrm{L}_{1} \mathrm{y} \mathrm{L}_{2}$, producen cantidades elevadas de ácido láctico en contraposición con L. brevis (cepa control), por su parte, la mayor producción de dicho compuesto se le atribuyó a L2. El viraje de color del medio se debió a la reducción del pH por acción del ácido láctico (datos no mostrados), tal como lo afirman ÁVILA et al. (2010b) al evaluar la producción de ácido láctico en cepas de Lactobacillus extraídas del tracto intestinal de animales de granja. Los microorganismos pertenecientes al género Lactobacillus tiene la capacidad de producir ácido láctico a partir de la degradación de carbohidratos simples o complejos. En este sentido, JURADO et al. (2009) evaluaron la producción de ácidos orgánicos en cepas de Lactobacillus aisladas de cerdos, clasificando estas en homo y heterofermentativa según la cantidad y variedad de ácidos detectados.

Fermentación de carbohidratos: La fermentación de los carbohidratos se evidenció por la acidificación del medio de cultivo y el viraje de color del indicador de pH (Fucsia a pH ácido y amarillo a pH alcalinos o neutros) (GUSILS et al., 2001). En la Tabla 2 se presenta la fermentación de los carbohidratos por parte de las cepas L1, L2 y L. brevis (como control), en esta se puede observar que la cepas tienen un patrón de fermentación de carbohidratos similar entre sí, fermentando la mayoría de los monosacáridos y disacaridos. El perfil de fermentación presentado por las cepas L1, L2 y L. brevis, es semejante al presentado por el género Lactobacillus, según GUSILS et al., (2001); ZAMUDIO y ZAVALETA, (2003).

Tabla 2. Fermentación de carbohidratos.

\begin{tabular}{|c|c|c|c|}
\hline Carbohidratos & $\mathbf{L}_{1}$ & $\mathrm{~L}_{2}$ & L. brevis \\
\hline Lactosa ${ }^{* *}$ & - & + & + \\
\hline Arabinosa* & + & - & - \\
\hline Manosa* & + & + & + \\
\hline Xilosa* & + & - & - \\
\hline Manitol $^{\star \star *}$ & - & - & + \\
\hline Celobiosa** & + & - & + \\
\hline Inositol| $^{* \star *}$ & - & - & - \\
\hline D- Sorbitol*** & - & - & - \\
\hline Galactosa* & - & + & + \\
\hline Glucosa* & + & + & + \\
\hline Fructosa* & + & + & + \\
\hline Maltosa ${ }^{* \star}$ & - & + & + \\
\hline Sacarosa** & + & + & + \\
\hline
\end{tabular}

Fermentación: positiva $(+)$, negativa $(-)$; Carbohidratos: monosacáridos $\left(^{\star}\right)$, disacáridos $\left(^{* *}\right)$ y Polisacáridos $\left(^{* *}\right)$. 
Resistencia a ácidos: Las cepas evaluadas presentaron colonias viables, en todos los valores de $\mathrm{pH}$ de referenciados, con un aumento progresivo de células viables a medida que el $\mathrm{pH}$ se acercaba a la neutralidad, esto permitió clasificar a la cepas como M.O acidófilos (Tabla 3). Resultados similares, fueron encontrados por SÁNCHEZ et al., (2011). Por otra parte ÁVILA et al., (2010b) observaron crecimientos elevados a $\mathrm{pH} 4$ y 5 , con una reducción del número de celulas viables a $\mathrm{pH}$ 6,5; este último, difiere de los resultados hallados en este estudio. La capacidad de crecimiento de M.O en ambientes ácidos es esencial para realizar cultivos probióticos eficientes.

Tabla 3. Crecimiento con diferentes valores de $\mathrm{pH}$.

\begin{tabular}{ccccc}
\hline Valores de $\mathrm{pH}$ & $\mathrm{L}_{1}$ & $\mathrm{~L}_{2}$ & L. brevis & Control \\
\hline 2,5 & + & + & + & - \\
3,00 & + & + & + & - \\
3,5 & ++ & ++ & ++ & - \\
4,00 & +++ & +++ & ++++ & - \\
4,50 & +++ & +++ & +++ & - \\
5,00 & +++ & +++ & +++ & - \\
5,50 & +++ & +++ & +++ & - \\
6,00 & +++ & +++ & +++ & - \\
6,50 & +++ & +++ & +++ & - \\
\hline
\end{tabular}

(-): no se evidenció crecimiento; (+): Buen crecimiento; (++): excelente crecimiento; $(+++)$ : crecimiento excesivo. Análisis de crecimiento basado en tamaño y número de colonias.

Temperatura óptima de crecimiento: Las cepas $L_{1}$ y $L_{2}$ presentaron crecimiento en un rango amplio de temperaturas que van desde los $18^{\circ} \mathrm{C}$ hasta los $40{ }^{\circ} \mathrm{C}$, (Tabla 4). Estos resultados permiten clasificar a las cepas evaluadas como mesófilas. Por su parte, ZAMUDIO y ZAVALETA, (2003), registraron crecimientos intermitentes entre cepas de Lactobacillus, donde de ocho especies estudiadas cuatro presentaron crecimiento a $15^{\circ} \mathrm{C}$, obteniendo un comportamiento similar a los $45^{\circ} \mathrm{C}$.

Tabla 4. Efecto de la temperatura en el crecimiento de los aislados.

\begin{tabular}{ccc}
\hline Temperaturas de crecimiento & $\mathrm{L}_{1}$ & $\mathrm{~L}_{2}$ \\
\hline $4^{\circ} \mathrm{C}$ & - & - \\
$18^{\circ} \mathrm{C}$ & + & + \\
$20^{\circ} \mathrm{C}$ & + & + \\
$25^{\circ} \mathrm{C}$ & ++ & ++ \\
$30^{\circ} \mathrm{C}$ & ++ & ++ \\
$35^{\circ} \mathrm{C}$ & +++ & +++ \\
$38^{\circ} \mathrm{C}$ & +++ & +++ \\
$40^{\circ} \mathrm{C}$ & +++ & +++ \\
$45^{\circ} \mathrm{C}$ & - & - \\
$50^{\circ} \mathrm{C}$ & - & - \\
\hline
\end{tabular}

$(-)$ : no se evidenció crecimiento; (+): Buen crecimiento; (++): excelente crecimiento; $(+++)$ : crecimiento excesivo. Análisis de crecimiento basado en tamaño y número de colonias.
Identificación Molecular: La Identificación Molecular permitió identificar al aislado $\mathrm{L}_{2}$, como Lactobacillus sp., con una cobertura del $97 \%$ y una identidad del $94 \%$, dichos valores de confiabilidad no son suficientes para identificar al microorganismo a nivel de especie.

Inhibición de patógenos: Por medio de esta prueba se determinó la capacidad de las cepas para inhibir el crecimiento de microorganismos patógenos (Tabla 5), a través de la observación de halos de inhibición, producidos por parte de las cepas evaluadas estudiadas.

Tabla 5. Perfil de inhibición de patógenos.

\begin{tabular}{|c|c|c|c|c|}
\hline \multirow{2}{*}{ Patógenos } & \multicolumn{3}{|c|}{ Aislados } & \multirow{2}{*}{ Control } \\
\hline & $L_{1}$ & $\mathrm{~L}_{2}$ & L. brevis & \\
\hline Staphilococcus aureus & + & + & + & - \\
\hline Staphilococcus spp & + & + & + & - \\
\hline Pseudomona aeruginosa & + & + & + & - \\
\hline Echerichia coli & + & + & + & - \\
\hline E. coli enteromasiva & + & + & + & - \\
\hline Moraxella catarralis & + & + & + & - \\
\hline Salmonella spp & - & + & + & - \\
\hline Bacillus spp & + & + & + & - \\
\hline Bacillus amyloliquefaciens & + & + & - & \\
\hline Bacillus subtilis & + & + & - & - \\
\hline Pseudomona putida & - & + & - & - \\
\hline Enterococcus spp & - & + & + & - \\
\hline Enterococcus fecalis & + & + & + & - \\
\hline Enterobacteria & + & - & - & - \\
\hline
\end{tabular}

Presencia de halo de inhibición (+); Sin presencia de halo de inhibición (-).

La cepa identificada hasta los momentos como L2, presentó antagonismo ante casi todas las cepas patógenas evaluadas menos en Enterobacteria. Tal como lo señala VALLEJO et al. (2008) las BAL tiene la capacidad de inhibir bacterias provenientes de nichos ecológicos similares como Escherichia coli, la importancia de dicha peculiaridad, se debe a que las unidades de producción y la salubridad a nivel nacional e mundial se ven afectadas por dicho patógeno y otras enterobacterias, el cual ha llegado a causar la muerte de gran cantidad de individuos, en este sentido, la cepas aquí evaluadas, presentaron inhibición in-vitro ante dichos patógenos, además de otros géneros de importancia en la producción agropecuaria. Del mismo modo, JURADO et al. (2009), pudieron observar inhibición frente a cepas de E. coli, Staphilococcus aureus, y Pseudomona aeruginosa, a través de una investigación orientada a la caracterización de bacterias probióticas aisladas del intestino grueso de cerdos. 


\section{Conclusiones y recomendaciones}

La caracterización de los aislados permitió seleccionar dos cepas identificadas como $\mathrm{L}_{1} \mathrm{y}_{2}$ cuyas características macro y micromorfológicas, fisiológica, bioquímicas y moleculares las colocan dentro del grupo de bacterias acido lácticas correspondientes al género Lactobacillus. No obstante dichas características no son suficientes para garantizar el uso de dichos microorganismos en la alimentación animal y/o humana. Es necesario indicar que la flora microbiana gastrointestinal de animales en la región zuliana, poseen cepas bacterianas (Lactobacillus) con facultades biotecnológicas que pudieran ser usadas para optimizar la producción, el aseguramiento de la higiene intestinal y el aprovechamiento de metabolitos poco digeribles, sin causar impactos negativos sobre el medio ambiente, lo que se pueden lograr a través del suministro directo o indirecto de dichas cepas. Dichos rasgos abren la puerta a un sinfín de oportunidades para los pequeños y medianos productores, al representar estos M.O. una alternativa viable para el desarrollo zona, al ser esta un área dedicada a la producción agrícola y pecuaria. Por otra parte, el estudio actual es el primero en su tipo, realizado en la Región del sur del Lago de Maracaibo.

\section{Referencias}

ANADÓN, A.; ROSA MARTÍNEZ-LARRAÑAGA, M.; ARANZAZU MARTÍNEZ, M. 2006. Probiotics for animal nutrition in the European Union. Regulation and safety assessment. Regulatory Toxicology and Pharmacology 45 (1):91-95.

ÁVILA, J.; ÁVILA, M.; TOVAR, B.; BRIZUELA, M.; PERAZZO, Y. 2010a. Capacidad probiótica de cepas del género Lactobacillus extraídas del tracto intestinal de animales de granja. Revista cientifica FCV-LUZ XX (2):161-169.

ÁVILA, J.; ÁVILA, M.; TOVAR, B. 2010b. Determinación de las condiciones de crecimiento in vitro de una cepa probiótica (Lactobacillus delbruekii subsp. bulgaricus) aislada del tracto intestinal de terneros (Bos taurus). Revista Venezolana de Ciencia y Tecnología de Alimentos 1 (1): 58-69.

BOONE, D. R.; CASTENHOLZ, R. W.; GARRITY, G. M. (EDS.). Bergey’s Manual® of Systematic Bacteriology. New York, NY: Springer New York, 2001.

CHENG, H.; HU, C.; LIN, S.; WANG, J.; LIU, J.; CHEN, Y. 2014. Characterization of two truncated forms of xylanase recombinantly expressed by Lactobacillus reuteri with an introduced rumen fungal xylanase gene. Enzyme and Microbial Technology 64-65:6-10.

GUARNER, F.; SCHAAFSMA, G. 1998. Probiotics. International Journal of Food Microbiology 39 (3):237-238.

GUSILS, C.; FIGUEROA, R.; CHAIA, A.; GONZÁLEZ, S.; OLIVER, G. 2001. Identification of lactic acid bacteria and enterobacteria. A technique in microplates. Interciencia 26 (11):563-566.

GUTIÉRREZ, L.; GÓMEZ, A.; ARIAS, L.; TANGARIFE, B. 2007. Evaluación de la viabilidad de una cepa probiótica nativa de Lactobacillus casei en queso crema. Revista Lasallista de Investigación 4:37-42.

HSUEH, H.; YU, B.; LIU, C.; LIU, J. 2014. Increase of the adhesion ability and display of a rumen fungal xylanase on the cell surface of Lactobacillus casei by using a listerial cell-wall-anchoring protein. Journal of the Science of Food and Agriculture 94 (3):576-584.

JURADO, H.; AGUIRRE, D.; RAMIREZ, C. 2009. Caracterización De Bacterias Probióticas Characterization of Isolated Probiotic Bacteria of the Large Intestine of Pigs As Alternative To Using Antibiotics. Revista MVZ Córdoba 14 (2):1723-1735.

LANE, D.; PACE, B.; OLSEN, G.; STAHL, D.; SOGIN, M.; PACE, N. 1985. Rapid determination of 16S ribosomal RNA sequences for phylogenetic analyses. Proceedings of the National Academy of Sciences of the United States of America 82 (20):6955-9.

PATTERSON, J.; BURKHOLDER, K. 2003. Application of prebiotics and probiotics in poultry production. Poultry science $82(4): 627-631$. 
RONDÓN, A.; SAMANIEGO, L.; BOCOURT, R.; MILIÁN, G.; RANILLA, M. J.; LAURECIO, M.; PÉREZ, M. 2008. Aislamiento, identificación y caracterización parcial de las propiedades probióticas de cepas de Lactobacillus sp. procedentes del tracto gastrointestinal de pollos de ceba. Ciencia y Tecnologia Alimentaria 6 (1):56-63.

SÁNCHEZ, L.; VICHI, J.; LLANES, M.; CASTRO, E.; SOLER, D.; ESPINOSA, I,; KOCIUBINSKI, G.; FERREIRA, C. 2011. Aislamiento y caracterización in vitro de cepas de Lactobacillus spp. como candidato a probióticas. Revista de Salud Animal 33 (3):154-160.

SORIANO, A.; MAMUAD, L.; KIM, S.; CHOI, Y.; JEONG, C.; BAE, G.; CHANG, M.; LEE, S. 2014. Effect of Lactobacillus mucosae on In vitro Rumen Fermentation Characteristics of Dried Brewers Grain, Methane Production and Bacterial Diversity. Asian-Australasian Journal of Animal Sciences 27 (11):1562-1570.

VALLEJO, M.; MARGUET, E.; ETCHECHOURY, V. 2008. Potencial probiótico de cepas de Lactobacillus aisladas de queso ovino. Revista de la Facultad de Salud Pública y Nutrición 9 (4):11-19.

ZAMUDIO, K.; ZAVALETA, A. 2003. Estudio del potencial probiótico de lactobacilos aislados de fuentes naturales. Ciencia e Investigacion 6 (1):30-35. 